\title{
Orígenes de la disciplina de la Gestión de Recursos Humanos en una Facultad de Economía y Negocios
}

\author{
Eduardo acuña A.
}

Facultad de Economía y Negocios

Universidad de Chile

eacuna@fen.uchile.cl

José Antonio Muga M.

Facultad de Economía y Negocios

Universidad de Chile

jmuga@fen.uchile.cl

Francisco Trincado M.

Magíster Gestión de Personas

Facultad de Economía y Negocios

Universidad de Chile

Pedro Pedreros M.

Magister Gestión de Personas

Facultad de Economía y Negocios

Universidad de Chile

\begin{abstract}
This paper describes and analyses the evolution of the Human Resources Management Discipline in its evolution, genesis process, development, change and institunalization at the current Business Management School (FEN) at the Universidad de Chile from a historical and heuristic perspective from the 19581973 period.
\end{abstract}


Keywords: Institution, origins, human resource management, agents, political dynamics.

\section{Resumen}

Este trabajo busca describir y analizar la evolución de la disciplina de la Gestión de Recursos Humanos en su proceso de génesis, desarrollo, cambios e institucionalización en la actual Facultad de Economía y Negocios de la Universidad de Chile desde una perspectiva de una narrativa histórica-heurística en el período comprendido entre 1958 y 1973.

Palabaras clave: Institución, orígenes, gestión de recursos humanos, agentes, dinámicas de la política.

\section{Introducción}

Este trabajo indaga en los orígenes y tempranas transformaciones de la disciplina en Gestión de Recursos Humanos (GRH) en la Facultad de Economía y Negocios (FEN) de la Universidad de Chile, entidad de carácter pública.

El estudio tiene el propósito de realizar una narrativa interpretativa, históricamente fundada (Skocpol, 1995, Suddaby et al. 2014; Fear, 2014), acerca de la génesis, realizaciones y cambios institucionales de esa disciplina durante el período 1958-1973. La narrativa pone de manifiesto que esos cambios estuvieron arraigados en una agencia en que participaron distintos actores en el contexto de la historia social, económica y política de la sociedad chilena correspondiente a dicho período (Silva, 2012; Salazar y Pinto, 1990; 2002). La narrativa plantea que ese ciclo, con su inicio y término, delimita la primera fase en la construcción de la GRH en la FEN, a la que se suceden varias otras hasta la actualidad, lo que amerita ser abordado separadamente en nuevos trabajos por la complejidad de 
las rupturas históricas que ocurren en la sociedad chilena a partir del golpe militar en 1973 (Salazar, 2015).

El interés en la génesis de la GRH ha tenido en referencia estudios que indagan en los orígenes institucionales de teorías y métodos en el campo de la teoría organizacional, la escuela de relaciones humanas, el comportamiento organizacional, el entrenamiento grupal y el liderazgo, todos estos fueron creados en universidades. Esos estudios contribuyen al desarrollo de este trabajo al mostrar cómo por medio de la perspectiva histórica se develan aspectos inéditos en la construcción de esas instituciones en interconexión con contextos espaciales y temporales específicos (Highhouse, 2002; Perrow, 1990; Hassard, 2012; O’Connor, 1999).

Para facilitar el entendimiento del caso hacemos un prolegómeno que establece direccionalidad y límites para este trabajo. En términos generales, el caso está relacionado con la evolución histórica que ha tenido la gestión de recursos humanos, principalmente en Estados Unidos, países europeos y Japón, en el siglo XX. Esa evolución plantea que la GRH, básicamente, ha estado orientada a cubrir tres áreas interconectadas, las relaciones de trabajo, las relaciones de empleo y las relaciones industriales (Gospel, 2013). Un segundo aspecto importante para el abordaje del caso ha sido el tener en consideración que los contextos tecnológicos, de mercado, políticos y sociales han desempeñado un papel trascendente en las formas cómo la gestión del trabajo ha evolucionado en los países antes señalados (Kaufman, 2008). Un tercer aspecto que distingue al caso en estudio es que este, por el período que abarca entre 1958 y 1973, tiene una estrecha correspondencia con los desarrollos en gestión de personal que ocurrieron en las potencias industriales de esa época, Estados Unidos, Gran Bretaña, Alemania, Francia y Japón. En esas sociedades se afrontaban los desafíos del industrialismo mediante la puesta en práctica de nuevos arreglos de organización del trabajo y el mantenimiento de relaciones industriales tripartitas, entre Estado, empresarios y trabajadores (Kerr et al. 1963). Un cuarto aspecto 
destacable es el importante papel que tienen universidades, particularmente de Estados Unidos, en la creación de conocimientos y métodos para entender e intervenir en las complejidades del trabajo en organizaciones y la sociedad según la óptica de distintas disciplinas de las ciencias sociales, la economía, sociología, psicología y ciencias políticas (Perrow, 1990). El trabajo de las universidades fue también determinante en la profesiona-lización de la GRH al integrar, como parte de sus actividades educacionales, la oferta de programas que legitimaban la especialización en dicho campo (Amdam, 2013). Por último hacemos ver que el desenvolvimiento de la GRH aparenta haber ocurrido en el contexto de regímenes capitalistas, principalmente en el mundo occidental, donde el conocimiento y la tecnología del management han estado puestos al servicio de empresas y organizaciones reguladas por las dinámicas del mercado (Kaufman, 2008). Este aspecto es de suma consideración para el caso que se aborda en este trabajo.

El objetivo global de este escrito es elaborar una narrativa que permita un entendimiento histórico-heurístico de los orígenes y tempranas transformaciones institucionales de la disciplina de GRH en la FEN, Universidad de Chile, en el período 1958-1973. Ese entendimiento considera el contexto social, político y económico de la sociedad chilena de esos años y sus influencias en el desarrollo de esa institución. Objetivos específicos son: explicar cómo la génesis de la disciplina supuso una confluencia de intereses y de actores que impulsaron al emprendimiento y sus posteriores realizaciones. Luego se busca explicar el desarrollo de la institución de GRH y la legitimidad que recibió de audiencias internas y externas a la FEN. Un tercer objetivo es conocer respecto de las inestabilidades y cambios que afectaron a la institución como consecuencia de las radicales y conflictivas mutaciones políticas, económicas e ideológicas que ocurrieron en la sociedad. El estudio concluye señalando los principales aprendizajes conseguidos en el análisis de las raíces históricas de la GRH. 
Los contenidos del trabajo se presentan del siguiente modo: primero se informa acerca del marco teórico y a continuación se explica la metodología que fundamenta el estudio. Luego se presenta y analiza el caso en sus aspectos más destacables, para finalmente establecer las conclusiones.

\section{Aspectos teóricos}

\section{A. Organización, institución e historia}

Para acometer con los objetivos de este trabajo se ocupa el análisis institucional de organizaciones, el que se bifurca en dos corrientes, una centrada en el estudio de cambios institucionales y, la otra, en la indagación de funciones y formas organizacionales (Brint y Karabel, 1991; DiMaggio y Powell, 1991; Greenwood, et al. 2014). En el trabajo se adopta el enfoque que examina los cambios institucionales teniendo en vista que el caso refiere a la génesis de la GRH, con lo que el estudio incorpora necesariamente la visión histórica (Skocpol, 1995, Suddaby et al., 2014; Fear, 2014). A partir de esa opción se considera particularmente propicio recurrir a las contribuciones seminales de la escuela desarrollada por Selznick (1957, 1996), Suddaby et al. (2014), la que permite entender por qué se adoptan ciertas formas organizacionales entre alternativas posibles, y por qué esas formas cambian de una cierta manera con el tiempo (Brint y Karabel, 1991).

Esa escuela considera que las organizaciones como tales se constituyen en instituciones cuando la autoridad, en acciones de liderazgo, infunden valores que comunican una identidad distintiva a la organización y a sus miembros al mostrar experticia en actividades que son valoradas en el contexto institucional en que se desenvuelve. Selznick entiende que la institucionalización es un proceso, "es lo que le ocurre a la organización a través del tiempo, reflejando su propia historia, la gente y los grupos que han 
participado en ella, los intereses creados y la forma como se ha adaptado a los cambios. El aspecto más significativo de institucionalizar es la infusión de valores que van más allá del cumplimiento de tareas técnicas" (1957, pág.16).

Para el sostenimiento de la identidad a las autoridades les corresponde desarrollar diversas acciones políticas, el establecimiento de una ideología administrativa con sus respectivos programas, estructuras y procedimientos; formar una elite organizacional que sea responsable de proteger y hacer sustentable la identidad en el tiempo; y el desarrollar una defensa estratégica de la institución frente a grupos de intereses poderosos, externos e internos, orientados a controlar la organización y sus recursos. Para entender el desarrollo institucional de una organización es indispensable acceder al conocimiento de su historia, pues ella es reveladora de los orígenes y transformaciones que han ocurrido con el tiempo (Skocpol, 1995, Suddaby et al. 2014).

\section{B. Génesis y realizaciones}

Brint y Karabel (1991), en el estudio de un cambio institucional en una organización educacional de Estados Unidos, plantean que para entender los orígenes de ese cambio es necesario distinguir entre la génesis de intereses y las realizaciones transformativas propiamente tales.

Los autores señalan que la gestación de intereses se arraiga en centros de poder en la sociedad que implican oportunidades y restricciones para el cambio institucional en educación. Uno es el mercado laboral, el que, en las preferencias que en él se manifiestan por el entrenamiento de ocupaciones más o menos lucrativas y prestigiosas, influye notablemente en el proceso de instalación de la nueva institución educacional. Algo similar ocurre con las organizaciones, especialmente grandes corporaciones, las que por 
sus estructuras ocupacionales y políticas de contrataciones de personal son focos de un gran poder estructural que significa oportunidades o restricciones para la implantación del cambio educacional. A estos centros se agrega el aparato burocrático estatal que tiene una función determinante en la legitimación de la institución educacional. Por otra parte, el mercado afecta la oferta de nuevos programas considerando la competición en la industria. Los activos e ideología de la nueva organización son igualmente importantes para su posicionamiento en la sociedad. El liderazgo de las elites que dirigen y mantienen el cambio institucional influyen poderosamente en el carácter innovador del cambio.

\section{Cambios y politica}

Los cambios institucionales pueden tomar distintas formas dependiendo de las características de la organización que es objeto de transformación y de las características del contexto político. Eso puede significar la realización de cambios abruptos y totales, o bien, mutaciones parciales, las que en sus agregaciones sucesivas pueden significar grandes transformaciones. La creación, mantenimiento y modificaciones institucionales son resultados de la agencia de actores, que según el poder político de que disponen, desarrollan distintas estrategias para consumar las transformaciones (Hall, 2010; Mahoney y Thelen, 2010).

Destacamos dos estrategias para la realización de cambios institucionales, una por extensión y otra por conversión (Mahoney y Thelen, 2010). La estrategia por extensión corresponde a nuevas funciones e interpretaciones que se adicionan a un orden institucional ya establecido. Esa estrategia supone ser resultado de las iniciativas de una coalición de agentes innovadores quienes valoran la agregación de nuevos arreglos porque son ventajosos para el desarrollo del orden institucional ya existente. Sin embargo, esas iniciativas tienen límites en su autonomía, porque las autoridades de 
ese orden disponen de la potestad para vetar y controlar la evolución de las propuestas innovadoras. Bajo esas circunstancias las mutaciones tienden a ser incrementales e intermitentes por la capacidad de veto que imponen las autoridades.

Por otra parte, referimos a la estrategia de cambio por conversión, la que supone la intervención de coaliciones políticas oportunistas que buscan la transformación de una institución ya existente por una nueva, aprovechando el estatus jurídico, recursos y espacialidad de la anterior institución. La coalición realiza la conversión mediante un nuevo marco interpretativo e identidad que permite el usufructo del antiguo orden. La conversión resulta de la participación de una coalición política oportunista, que en lugar de desmantelar la antigua institución, la usa de un modo innovador mediante la explotación de ambigüedades. Los cambios por conversión suelen ser rápidos y radicales cuando hay un contexto político con poca o ninguna capacidad de veto.

Para que los cambios institucionales prosperen es indispensable que las coaliciones políticas que impulsan las innovaciones consigan que audiencias internas y externas asociadas con la organización mantengan un respaldo político continuo a los cambios, lo que está condicionado por la afinidad que aquellos tienen con los intereses de las audiencias. Si ese respaldo se fractura o quiebra, los cambios institucionales pueden entrar en declinación, salvo que, debido a las circunstancias de poder, la coalición interna tenga la capacidad de hacer ajustes en sus estructuras y esquemas interpretativos que sean adaptativos a los requerimientos externos (Dutton, y Dukerich, 1991; Gioia, et al., 2010).

\section{Instituciones y legitimidad}

Amplificamos la dimensión política de los cambios institucionales considerando cómo estos no solo necesitan de recursos e información sino que también deben disponer de legitimidad, vale 
decir, que sean creíbles y aceptados según un sistema socialmente construido de normas, valores y creencias (Scott, 2014; Clegg et al., 2007; Gioia y Chittipeddi, 1991). Suchman (1995) distingue tres tipos de legitimidad organizacional: pragmática, moral, y cognitiva. La pragmática está orientada a servir a los intereses de audiencias más inmediatas y de la sociedad en general. La legitimidad moral refiere a conseguir una evaluación normativa positiva según los juicios de audiencias externas que tienen en cuenta los resultados, las técnicas, procedimientos y estructuras que se ocupan en las actividades organizacionales. La legitimidad cognitiva supone la existencia de modelos culturales que hacen comprensible a la organización, a las actividades que realiza, todo ello transmite cercanía con las creencias y experiencias cotidianas de audiencias.

Por otra parte, Suchman aborda la gestión de legitimidad considerando tres desafíos de legitimación: ganar, mantener y reparar legitimidad. Ganar legitimidad es particularmente importante cuando la puesta en marcha de nuevas operaciones son técnicamente problemáticas o están poco institucionalizadas. Una forma de abordar proyectos pioneros es integrando las nuevas actividades en el contexto de sectores que cuenten con legitimidad ya validada, sin embargo para los emprendedores esa opción puede resultar poco atractiva porque puede significar poner a las nuevas operaciones en situación marginal e incluso ilegítima. El mantenimiento de legitimidad es menos complejo porque una vez que esta es conseguida tiende a permanecer en una inercia de atribución de legitimidad que se da por descontada. Las estrategias para el mantenimiento de legitimidad son básicamente de dos tipos, una es la adaptación anticipada ante cambios futuros y el proteger los logros alcanzados. La reparación de legitimidad generalmente es reacción a una crisis no anticipada por los líderes organizacionales. La reparación de legitimidad considera: comunicar un relato normalizador que separa la crisis de evaluaciones generales que pongan en tela de juicio la legitimidad de toda la organización. Otra 
es la realización de reestructuraciones estratégicas que expresan la decisión de impedir la ocurrencia de faltas similares en el futuro.

\section{E. Agentes sociales}

Referimos a tipos de agentes que por lo común influyen directa o indirectamente en la creación, mantenimiento o cambio de instituciones (Alvesson, et al., 2008; Scott, 2014).

Un importante agente es el Estado, el que provee un marco legal que coactivamente influye en cómo se estructuran, funcionan y relacionan distintos agentes en la sociedad. Ese marco legal define la naturaleza, los derechos y capacidades políticas de actores para intervenir en el desarrollo de instituciones, lo que también afecta a la propia esencia institucional del Estado. Este, por el poder político que tiene en el establecimiento de contextos y arreglos institucionales, es foco de acciones de múltiples agentes quienes buscan modificar las "reglas del juego" para que estas sean afines a sus intereses (Buchelli y Kim, 2014; Millward, 2013).

En las economías capitalistas las grandes organizaciones privadas tienen una agencia importante en la construcción de instituciones por el poder que tienen en recursos, por la capacidad de movilización de estos, y por la disponibilidad de extensas redes de apoyo político que permiten condiciones para la realización de negocios. Los directivos, trabajando estratégicamente en alianza con otras organizaciones, suelen negociar con el Estado el mantenimiento o cambio de instituciones favorables a sus propósitos.

Las profesiones son también relevantes en la mejora o creación de instituciones al contribuir con nuevos conocimientos y acciones prácticas para la realización de actividades en la esfera de organizaciones y de la sociedad. A la base de esas contribuciones está el trabajo que investigadores realizan en universidades, que desde distintos saberes formulan modelos cognitivos, normativos o 
regulatorios que permiten el entendimiento y soluciones más efectivas de problemas (Amdam, 2013).

Las asociaciones al representar los intereses de grupos afiliados a ellas, a nivel local, nacional o internacional, afectan también en el desarrollo de instituciones. Las asociaciones son instrumentos políticos, que en la unión de sus participantes se posicionan en el orden institucional para hacer valer y fortalecer sus identidades ante sus propias audiencias internas, y muy especialmente ante audiencias externas (Scott, 2014).

Por último destacamos a los movimientos sociales en su capacidad de agencia en cambios institucionales. Mediante la organización incipiente de movilizaciones colectivas los ciudadanos se convocan para resistir o luchar por la consideración de sus inquietudes e intereses a nivel de contextos institucionales amplios o arreglos institucionales específicos en organizaciones. La agencia de los movimientos sociales suele llevarse a cabo de dos maneras: una es mediante el desarrollo de acciones contestatarias desde fuera del orden institucional que cuestionan, o bien desde el interior de dicho orden (Scott, 2014).

\section{Metodología}

El diseño metodológico de la investigación fue establecido en consideración al propósito de realizar una narrativa heurística e histórica que posibilitara el entendimiento de los orígenes y tempranas transformaciones de la disciplina de la GRH en la Facultad de Economía y Negocios (FEN) de la Universidad de Chile (Czarniawska, 2004; Boje, 2001; Suddaby, et al., 2014). Ese diseño se enmarcó en una metodología etnográfica, la que implicó el uso de distintos métodos para la recolección e interpretación de datos

La selección del caso consideró el hecho que en esa Facultad no hay pesquisas que informen acerca de la historia de la GRH en esa organización universitaria y en el contexto de la sociedad. En la 
selección también se ha tenido en cuenta que la FEN, a lo largo de su existencia, ha sido centro descollante en la educación e investigación en management y en economía en Chile, lo que justifica indagar respecto de cómo esa experiencia se ha manifestado en el campo de la gestión de recursos humanos.

La recolección de datos tuvo por propósito el permitir un entendimiento retrospectivo de la construcción de la disciplina de la GRH en la FEN, teniendo en vista el contexto institucional e histórico de la sociedad chilena durante el período 1958-1973. Eso significó recurrir a fuentes primarias de datos mediante el uso de diferentes métodos. Se realizaron observaciones de las varias locaciones en los que ocurrieron los cambios, con lo que se pudo entender aspectos de la cultura universitaria y sus simbolismos expresados en edificaciones y artefactos (Schein, 1985). Se revisaron y analizaron publicaciones, documentos y archivos relativos a la historia de la Universidad y de la Facultad, lo que posibilitó un entendimiento total de los cambios y de sus fases (Departamento de Economía, 2009; Economía y Administración, 2014; Pedreros y Trincado, 2014; Clavel, 1984; Palma, 1974; Selume, 1986; Armstrong, 1975; Muga, 1975; Riveros, 2016). También se realizaron 10 entrevistas a profesores, laboralmente activos y retirados de la FEN, quienes por sus experiencias de trabajo fueron conocedores y protagonistas de la historia en la construcción de la disciplina en GRH (Hoggett, 2013). Las entrevistas fueron hechas bajo el encuadre de una conversación dialógica en la que se invitaba a los profesores a rememorar y narrar sus experiencias y significaciones al participar en el desarrollo de esa institución. Tres de los profesores entrevistados ejercieron cargos de autoridad durante ese desarrollo, por lo que sus relatos fueron especialmente reveladores acerca de las circunstancias y la forma cómo se encaró la génesis y realizaciones de la disciplina de GRH. Cada entrevista fue hecha, aproximadamente, en una hora, ellas fueron grabadas en audio y posteriormente transcritas para su análisis. 
Por otra parte, la recolección de datos también consideró el acceso a fuentes secundarias que posibilitaron conocer el contexto institucional político, social, económico y cultural de la sociedad durante los años en que ocurre la creación y tempranas transformaciones de la GRH. Para tales efectos se recopilaron y analizaron investigaciones, libros y artículos, los que contribuyeron a entender de qué manera el orden institucional, las circunstancias y los cambios políticos radicales que acontecen en la sociedad tuvieron una notable influencia en el curso que tomó el desarrollo de la GRH en la FEN (Montecino y Acuña, 2013; Mönckeberg, 2006; Silva, 2012; Salazar y Pinto, 2002; Salazar, 1990, 2015).

Para el análisis de los datos se ocupó el método hermenéutico, el que supuso por parte de los investigadores una postura de interrogación de los textos escritos, orales y materiales originados en la recolección de información. Esa postura interrogadora consideró tres objetivos por parte de los investigadores, uno era entender el pensamiento propio en el proceso de interrogación de los textos; otro era entender los significados manifiestos que estos contenían; y el tercero era interpretar los significados subyacentes o inconscientes a que daba lugar el escrutinio crítico de los datos (Alexandrov, 2009). Por otra parte, la información fue interpretada siguiendo los principios del círculo hermenéutico, el que consideró interrogaciones iterativas de los textos desde sus aspectos particulares a los generales y viceversa, hasta alcanzar una saturación interpretativa (Alvesson y Sköldberg, 2004).

El análisis de datos fue determinante en establecer la periodización 1958-1973 como la primera fase de construcción de la GRH en la FEN. En 1958 ocurrieron los eventos y circunstancias que significaron la génesis del proceso de cambio, mientras 1973, con el golpe militar, marcó el ocaso de la primera fase considerando las rupturas históricas que ese evento político desencadenó en la sociedad chilena (Salazar, 2015). 


\section{Presentación y análisis del caso}

A. $\quad$ Génesis de intereses (1958)

Los cimientos fundacionales de la GRH en la FEN fueron precedidos por una génesis de intereses en la que diversos agentes chilenos y extranjeros coincidieron en percibir ventajas en el proyecto para su posterior ejecución. En esa génesis tiene una función central la propuesta que la AID, organización del gobierno de Estados Unidos, hace a la FEN y a la Universidad de Chile para realizar un convenio de intercambio académico con la Universidad de Cornell en el campo de las Relaciones Industriales (Brint y Karabel, 1991; Buchelli y Kim, 2014; Pedreros y Trincado, 2014; Suchman, 1995; Millward, 2013; Selznick, 1957).

El convenio en Relaciones Industriales es ofertado a la FEN en el conocimiento que disponía la AID respecto del Instituto de Organización y Administración de Empresas (INSORA), el que desde su fundación en 1951 en la Facultad, estaba comprometido en contribuir al desarrollo industrial de Chile. Para estos efectos el Instituto se abocaba a la educación de ingenieros comerciales y de otras profesiones para mejorar la capacidad empresarial y la gestión de organizaciones privadas y públicas, a la vez que prestaba asistencia técnica mediante la introducción de nuevos enfoques humanistas que corrigieran la extrema racionalización del trabajo según los principios del taylorismo. La AID hizo su propuesta a sabiendas que las racionalizaciones del trabajo que efectuaba INSORA eran muy conflictivas y resistidas por trabajadores y sindicatos, ante ello el convenio con la Universidad de Cornell, por su experticia en relaciones industriales, prometía ser una importante contribución para modernizar a las empresas chilenas en forma conciliatoria entre trabajadores y empresarios (Clavel, 1984; Armstrong, 1975).

La posibilidad del intercambio académico despertó enorme interés en la Facultad y en INSORA porque posibilitaría el 
desarrollo institucional al incorporar, de manera inédita en Chile, la especialidad de las Relaciones Industriales. Esa especialidad no solo auguraba que INSORA podría continuar con sus actividades de racionalización, sino que además podrían ser expandidas a asesorías en las relaciones entre empresarios, trabajadores y sindicatos. El interés más relevante del convenio era la posibilidad de modernizar la educación profesional para ingenieros comerciales con nuevas teorías y métodos que permitieran armonizar la compleja ecuación entre la participación del factor humano en el trabajo y el logro de productividad (Palma, 1974; Mahoney y Thelen, 2010; Muga, 1975).

Por otra parte, para las autoridades universitarias el interés por el convenio se acrecentaba en el prestigio distintivo que podía deparar a INSORA y a la Facultad la colaboración con la Universidad de Cornell en el contexto universitario nacional. Las autoridades consideraban que el convenio representaba un calce de intereses afines con la ideología de la Facultad, con sus actividades académicas y con el cuerpo de profesores de INSORA, quienes, por sus experiencias, podrían asumir responsabilidades en el convenio. A su vez, para la AID, la consumación del convenio con INSORA era también motivo de mucha valoración, por los activos que simbolizaba su afiliación con la Universidad de Chile en su condición de principal entidad universitaria pública de notable figuración nacional. Por su parte la FEN también simbolizaba activos institucionales destacables en su trayectoria de centro universitario dedicado a la educación y estudio de la Economía y de la Administración. Esos activos dieron garantía a la AID que el convenio disponía de un contexto universitario suficientemente robusto y comprometido que permitiera "el trasplante institucional" de las Relaciones Industriales desde la Universidad de Cornell a INSORA (Departamento de Economía, 2009; McKersie et al. 1986).

En la génesis de intereses para crear la institución de la GRH por medio de las Relaciones Industriales intervienen también centros de poder de la sociedad chilena que muestran interés en la iniciativa. 
Los grandes empresarios, los gobiernos y los economistas consideraban de gran urgencia disponer de profesionales y técnicos que respaldaran la planificación y ejecución del desarrollo industrial del país, poniendo coto a la burocracia, al burocratismo estatal y fortaleciendo la gestión de organizaciones públicas y privadas. Desde esos centros de poder hubo anuencia para acentuar la institucionalización de la carrera de Ingeniero Comercial en Administración extendiendo sus competencias en la especialidad de Relaciones Industriales. Esa especialidad vendría a suplir necesidades del mercado laboral de cuadros ejecutivos y técnicos capacitados para administrar organizaciones con métodos que pacificaran las conflictivas relaciones de trabajo entre empresarios, trabajadores y sindicatos, y que a la vez permitieran mancomunar voluntades para el logro de las actividades productivas (Brint y Karabel, 1991; Boroschek, 1975; Armstrong, 1975; Walker, 1975, 2003; Piccinini, 1975).

El convenio de la AID también despierta intereses arraigados en el contexto institucional económico, político y social de la sociedad de la época. La estrategia de desarrollo económico mediante la industrialización y sustitución de importaciones que se ocupaba en el país, careció del vigor suficiente por parte de los gobiernos y sus inestables coaliciones, para mantener políticas fiscales coherentes con el control en el gasto público e incentivos al crecimiento económico, todo ello se volvía más grave con los descontrolados procesos inflacionarios que desbarataban los proyectos de industrialización. Esas situaciones fueron caldos de cultivo para que la sociedad chilena de los años 50 fuera asolada por continuas huelgas y movilizaciones nacionales de trabajadores del sector público y privado quienes protestaban y resistían, en ocasiones con consecuencias de mucha violencia, las medidas salariales de los gobiernos que empobrecían las condiciones de vida de los trabajadores (Silva, 2012; Sunkel, 2011; Salazar, 1990; Suchman, 1995). 
Por último, en la génesis del convenio académico atribuimos a la AID una motivación ideológica mesiánica de influir en la política interna de la sociedad chilena teniendo en cuenta el marco de la "guerra fría" que envolvía a las relaciones internacionales en el mundo. La institucionalización de la Relaciones Industriales en las organizaciones chilenas bien podía ser un instrumento "científico" que ayudara a descomprimir la alta conflictividad laboral y de disturbios sociales, con lo que se evitaran los riesgos que el descontento popular hiciera, que en la elección de gobiernos venideros se perdiera el respaldo al capitalismo y, por el contrario, las preferencias de los ciudadanos se inclinaran por la instalación de un régimen socialista en la sociedad chilena (Buchelli y Kim, 2014; Suchman,1995). Esa motivación tiene asidero al considerar que la AID patrocinó un convenio entre la Universidad de Chicago y la Escuela de Economía y Administración de la Universidad Católica, el que permitió que economistas chilenos formados en Chicago instalaran el neoliberalismo en Chile en ceñida alianza con la dictadura militar (Valdés, 1989).

\section{B. Conformación de la identidad y realizaciones transformativas (1959-1968)}

La institucionalización de las Relaciones Industriales tomó un impulso inicial, en 1959, con la firma del convenio entre autoridades de la Universidad de Cornell y de la Universidad de Chile bajo el patrocinio de la AID. El convenio consideraba una duración de seis años, su objetivo central era la creación de un Departamento de Relaciones Industriales en la FEN, el que posibilitaría la educación de profesionales, la realización de investigaciones y actividades de asistencia técnica en organizaciones públicas y privadas. El convenio consideraba a INSORA como la entidad académica responsable de institucionalizar las Relaciones Industriales en la 
Facultad mediante la agregación de esa especialidad en sus actividades (Mahoney y Thelen, 2010)

Una realización trascendente de esa institucionalización fue el intercambio académico que ocurrió entre profesores de INSORA y de la Universidad de Cornell. Doce profesores de INSORA fueron enviados a Cornell, progresivamente, para participar y graduarse en el programa de Máster en Relaciones Industriales y del Trabajo (MILR), a la vez que un grupo de profesores de la Universidad de Cornell realizaron prolongadas estadías académicas en INSORA para colaborar en la consolidación del proyecto (Hall, 2010).

Los profesores chilenos, ya graduados en Máster en Relaciones Industriales por la Universidad de Cornell, tuvieron la responsabilidad de instalar la especialidad de Relaciones Industriales en INSORA. Esos profesores eran una elite que se distinguía por la formación de postgrado, única en Chile, y también por ser un grupo de economistas, administradores, psicólogos, sociólogos, historiadores y abogados que proyectaban un abordaje multidisciplinario para el estudio y práctica de la Administración. Esa elite fue la coalición política, que en alianza con las autoridades de la Facultad crean y consolidan la identidad de Relaciones Industriales como extensión de la institucionalidad de INSORA y de la Universidad. La elite de profesores encarnaba un sentido misionario de valores comprometidos con el desarrollo industrial de Chile mediante la incorporación de esa identidad en los planes de estudios de ingenieros comerciales y de otras profesiones, en la realización de investigaciones y en la ejecución de labores de asistencia técnica en relaciones de trabajo (Selznick, 1957). En la consolidación de los cambios institucionales fue muy determinante el respaldo político que significó el trabajo educacional y de investigación que profesores de la Universidad de Cornell y profesores chilenos efectuaron en INSORA, porque daban testimonios, que los cambios en la Facultad eran "trasplantes institucionales" que tenían suficiente fidelidad con las tradiciones y experiencias originarias en esa Universidad (McKersie et al., 1986; 
Landsberger y Canitrot, 1967; Landsberger y Dastres,1964; Morris, 1967; Barría, 1967; Barrera, 1969; Fuchs y Santibáñez, 1967; INSORA, 1969).

La teorización en que se fundamentan las Relaciones Industriales (RI) tuvo un papel muy importante en la sedimentación que la especialidad tiene en la Facultad, en INSORA y en la sociedad chilena. Particularmente destaca la adhesión al modelo de Relaciones Industriales que los profesores Kerr, Dunlop, Harbinson y Myers formularon en la década de los 50 en Estados Unidos, en plena "guerra fría", como respuesta al macartismo anticomunista y a la "lucha de clases" del marxismo. Esos profesores, autores del libro El Industrialismo y el Hombre Industrial (1963), plantean el sostenimiento del capitalismo por medio de la creación, mantenimiento y cambio de sistemas tripartitos de relaciones laborales cuyas normas regulatorias podían ser acuerdos conciliatorios legitimados con la participación de empresarios, trabajadores y el Estado, según las sociedades. A esa teorización se integraban otras contribuciones de las ciencias sociales, administración y economía que formaban un cuerpo de conocimientos coherentes para la gestión profesional de las organizaciones y de la fuerza de trabajo. En suma, la especialidad de RI ofrecía teorías y métodos actualizados para entender y solucionar los problemas de la Administración (Muga, 1975). Esa experticia posicionó a los profesores de INSORA con un poder de conocimiento que estimuló a la diseminación de las RI en otras Facultades y Escuelas de Economía, de Santiago, Valparaíso, e incluso en programas para graduados que se ofrecían a nivel de Latinoamérica.

La institucionalización de las RI se desarrolló en INSORA bajo el estatus de una unidad académica abocada al cultivo de esa especialidad, no alcanzando en esta etapa la condición de Departamento, lo que era objetivo que tempranamente estipulaba el convenio con la Universidad de Cornell (Mahoney y Thelen, 2010). INSORA, en su identidad de Instituto, destacaba de manera central 
por sus actividades dedicadas a la comercialización y realización de consultorías en organizaciones públicas y privadas. Ese aspecto de la identidad de INSORA influyó considerablemente en que la Unidad de Relaciones Industriales (URI) adoptara también la orientación hacia la prestación de servicios de consultoría. Sin embargo, la identidad de la URI consiguió también distinción al comprometer firmemente su quehacer en el ámbito académico, contribuyendo a la educación de ingenieros comerciales y de otras profesiones y en la realización de investigaciones (Clavel, 1984). La identidad de la URI se distinguió también por incorporar en sus intereses, influido por el ambiente político de la sociedad chilena, el estudio de la economía social de mercado según su práctica en Alemania Federal; las empresas gestionadas por trabajadores en Yugoslavia y el cooperativismo, todo esto expresaba un espíritu académico por expandir fronteras en el conocimiento. La identidad de la URI se proyectaba con un perfil atractivo de conocer internacionalmente, eso llevó a establecer lazos con la Organización Internacional del Trabajo (OIT) y el considerar la posibilidad de realizar intercambios académicos con profesores franceses en el campo de las RI.

Durante gran parte de los años que cubre este período la URI progresivamente fue consolidando su legitimidad, lo que respaldó su existencia en forma exitosa. Pilar central en esa legitimidad fue que las RI eran un isomorfismo institucional de correlato estrecho con las innovaciones de punta que ocurrían en el campo de la administración en las más destacadas Universidades de Estados Unidos y en las empresas de las principales potencias económicas del mundo. Ese isomorfismo institucional simbolizaba que la Universidad de Chile y la Facultad de la época, con la incorporación de URI, se situaba en posiciones de avanzada en la modernización académica en la disciplina de la administración tanto en la esfera universitaria como en el de las organizaciones chilenas. La legitimidad que alcanzó la URI se manifestó en reconocimientos de audiencias internas y externas de la Universidad que apreciaban las 
contribuciones pragmáticas que la Unidad había hecho en la diseminación de la especialidad en otras Universidades y Escuelas de Economía en Chile; en el mejoramiento de la capacidad de gestión en organizaciones; en la modernización de la carrera de Ingeniería Comercial y en la publicación de textos e investigaciones (Suchman, 1995; Armstrong, 2013; IAP, 1963). La legitimidad también se manifestaba en la esfera cultural porque las teorizaciones y las prácticas en RI que se comenzaron a difundir en la sociedad y empresas chilenas, por medio del modelo tripartito de relaciones industriales, hacían abrigar expectativas positivas de coexistencia entre capitalismo y socialismo, augurando una proyección sostenida del desarrollo industrial en el país. Sin embargo, el curso de los procesos políticos en la sociedad chilena, que anticipaban la posibilidad de transformaciones radicales entre la disyuntiva de mantener el capitalismo o construir un régimen socialista, hicieron que la legitimidad de las RI entraran en un período de estancamiento. La radicalidad de los cambios que se avizoraban en la sociedad chilena implicó grandes incertidumbres en las actividades universitarias, económicas y sociales, todo ello hizo que la institución de las RI no tan solo se detuviera en su desarrollo sino que comenzara un proceso involutivo.

\section{Desestabilización, declinación y conversión institucional de la identidad URI (1968-1973)}

Esta fase informa acerca de la desestabilización, declinación y conversión institucional que experimentó la URI como consecuencia de la extrema y violenta radicalización política-ideológica que ocurrió en la Universidad de Chile con la Reforma Universitaria; cuando en la sociedad, distintas coaliciones de partidos, disputaron el acceso al gobierno entre las opciones de instalar un régimen socialista de izquierda, uno socialista comunitario o bien conservar el capitalismo; luego con el despliegue de violentas acciones 
colectivas entre quienes apoyaban o resistían al gobierno socialista de la Unidad Popular elegido democráticamente (1970-73); y por último con el epílogo dramático del golpe militar que destituyó a ese gobierno socialista y puso término a un largo período de vida democrática en el país (1973). Esas circunstancias se entrecruzaban potenciando una creciente hostilidad política que progresivamente llevó a la casi total imposibilidad de convivencia ciudadana, porque individuos y grupos, en la identificación con las facciones en pugnas, perduraban estados mentales paranoides de guerra que movilizaban a la lucha y derrota de los adversarios (Riveros, 2016; Salazar, 1990; Montecino y Acuña, 2013; Departamento de Economía, 2009; Walker, 2003).

La Reforma en la Universidad de Chile fue un proceso largo, desgastante y violento que ocurrió entre 1968 y 1972, el que finalmente se consumó después de propuestas, contrapropuestas, negociaciones y renegociaciones en un nuevo Estatuto que definió el papel de la Universidad en consonancia con las necesidades de construir una sociedad más justa y solidaria. El Estatuto reformuló, entre otros aspectos, las actividades educacionales, de investigación y de extensión universitaria; la carrera académica; destacando también por la democratización que dio derechos a funcionarios, estudiantes y profesores para que participaran en decisiones, especialmente en la elección de autoridades académicas (Riveros, 2016; Garretón y Martínez, 1985).

El proceso de Reforma, en su prolongación e incertidumbre en resultados, desestabilizó de manera general el normal funcionamiento académico en la Universidad. La Facultad, de ese entonces, se vio particularmente afectada por los sucesivos disturbios entre bandos de estudiantes y profesores que buscaban el control de la Facultad y que llevaron a la escisión ideológica de sus actividades académicas (Departamento de Economía, 2009). Por su parte INSORA veía amenazada su identidad por el cuestionamiento que la Reforma hacía a la existencia de Institutos en la Universidad. La URI, en su pertenencia histórica a INSORA, compartía naturalmente 
esa amenaza, con lo que se ensombrecía el sentido de sus actividades y proyecciones futuras. El nuevo Estatuto sepultó finalmente la existencia de INSORA, y con ello la identidad de la URI, al promulgar que la Universidad de Chile consideraba como instituciones exclusivas de su quehacer académico a las Facultades, Departamentos y Escuelas. Con esa promulgación se eliminaba de plano la existencia de los Institutos, como el caso de INSORA, por considerar que eran organizaciones ajenas al trabajo académico al centrarse en la comercialización y en el lucro con sus actividades. Esa promulgación significó que la Facultad, para adecuarse a la nueva institucionalidad, debió realizar una conversión en sus estructuras dando origen a cinco Departamentos, de Economía, de Administración, de Contabilidad, de Administración Pública y el Departamento de Relaciones del Trabajo y Desarrollo Organizacional (DERTO), este último originario de la identidad de la URI (Mahoney y Thelen, 2010).

Por otra parte, la Reforma, para hacer viable el trabajo universitario tan severamente paralizado por el ideologismo reinante, determinó la constitución de cuatro sedes universitarias en Santiago (Norte, Sur, Oriente y Occidente), en cada una de estas se convocaba a la conformación de Facultades según afinidades ideológicas de los académicos, pro marxistas o no marxistas. Eso significó la existencia de dos Facultades de Economía, una en la Sede Norte correspondiente a la Facultad de Economía Política, de orientación marxista, y la otra la Facultad de Economía y Administración, no marxista (Departamento de Economía, 2009; Riveros, 2016; Garretón y Martínez, 1985). Esa escisión significó un severo golpe en la declinación de la URI porque un grupo importante de sus profesores dejaron la Unidad por sus preferencias para colaborar en el desarrollo de la Facultad de Economía Política. La partida de esos profesores fueron un cisma para el espíritu de cuerpo de la URI porque nunca antes había ocurrido una escisión por razones ideológicas, no obstante que era sabido que entre los profesores de la URI había un pluralismo político que era respetado 
y que no impedía el trabajo grupal. Ese cisma puede entenderse como resultante "natural" del cada vez más creciente fraccionamiento ideológico que ocurría en la sociedad que forzaba a tomar bando por posturas promarxistas o antimarxistas.

Otro factor importante que contribuyó a la desestabilización y declinación de la URI fue el hecho que algunos de los líderes fundadores de esa entidad dejaron el país durante el gobierno de la Unidad Popular motivados por acceder a empleos internacionales. Esas pérdidas de liderazgo pudieron ser suplidas y amortiguadas por la entereza de algunos líderes, también fundadores, que permanecieron en la Universidad sosteniendo la identidad de la URI y conduciendo a la nueva generación de profesores jóvenes que se habían ido integrando al grupo.

El golpe militar (1973), como parte de sus primeras acciones de gobierno, intervino el sistema universitario, dejando sin efecto las Reformas que se habían realizado en las universidades (Montecino y Acuña, 2013). Para el caso de la Universidad de Chile se ratificó el ordenamiento según facultades convencionales, con lo que se refrendó la existencia de la Faculta de Economía y Ciencias de la Administración (FACEA) y su composición departamental (Departamento de Economía, 2009). Con posterioridad al golpe, a FACEA le correspondió ocuparse de la reincorporación de profesores, estudiantes y funcionarios que se habían afiliado a la Facultad de Economía Política. Para el DERTO eso significó el recibimiento fraternal de profesores que habían emigrado a esa facultad, con ello se posibilitó la reinserción laboral de esos académicos.

\section{Conclusiones}

Este trabajo ha permitido la elaboración de una narrativa históricaheurística acerca de los orígenes y tempranas transformaciones de la institución académica de la GRH en la Facultad de Economía y 
Negocios (FEN) de la Universidad de Chile durante el período 1958-1973. La narrativa ha estado fundada en el institucionalismo histórico, el que ha permitido conocer de la génesis de intereses, realizaciones y cambios que afectaron la construcción de la GRH en el contexto político, social y económico de la sociedad chilena de aquellos años.

Un primer aspecto que destaca el caso es que el cimiento fundacional de la GRH en la FEN ocurrió mediante la institucionalización de las Relaciones Industriales con el propósito de desarrollar la formación de ingenieros comerciales y de otras profesiones; incrementar la capacidad de gestión en organizaciones privadas y públicas; realizar asistencias técnicas, investigaciones y el difundir sus resultados en la sociedad chilena. El caso ejemplifica un emprendimiento institucional al que sus líderes insuflaron una identidad distintiva en valores comprometidos con el desarrollo industrial del país (Hardy y Maguire, 2013). Esa identidad se fortaleció con los activos estratégicos, ideológicos y de recursos que la Universidad y la FEN aportaron al proyecto (Selznick, 1957). El estudio muestra que la institucionalización de las Relaciones Industriales en el período 1958-1973 fue afectada por tres ciclos, uno de consolidación, otro de estancamiento y declinación y un tercero que preserva el emprendimiento institucional. Esos ciclos son reveladores de que la evolución del emprendimiento fue muy sensible a las zigzagueantes condiciones políticas de la sociedad. (Lawrence, 2013).

El primer ciclo del emprendimiento consideró su inicio y su consolidación exitosa en una trayectoria de más de diez años (19581969). El emprendimiento, durante esa trayectoria, forjó y mantuvo una legitimidad pragmática, moral y social al cementar la Unidad de Relaciones Industriales en la FEN, lo que consideró valorados logros en la educación de ingenieros comerciales; en la asistencia técnica a organizaciones; y en la realización de investigaciones respecto de la realidad de las relaciones de trabajo en Chile (Suchman, 1997). Esa legitimidad estuvo respaldada por una 
coalición política, la que incorporó a agentes internos y externos a la Universidad. Un papel aglutinador importante en esa coalición lo tuvo la participación de la AID y la Universidad de Cornell, que por sus intermediaciones posibilitaron que en la FEN se realizara un "trasplante institucional" según las experiencias académicas que esa universidad tenía en Relaciones Industriales. Con ese "trasplante" la Facultad de la época alcanzó un isomorfismo respecto de los progresos que ocurrían en universidades y empresas de las grandes potencias económicas occidentales en el campo de la Administración, particularmente en la gestión del trabajo, con lo que también la Facultad se situó en una posición de avanzada en el contexto de las universidades y empresas chilenas. En las realizaciones que ocurren en este ciclo descuella la participación del grupo de profesores chilenos que se graduaron en la Universidad de Cornell, quienes fueron responsables de instalar y poner en marcha la especialidad de RI y, posteriormente, contribuyeron a su difusión en otras universidades y en organizaciones públicas y privadas en Chile.

El segundo ciclo, de estancamiento y declinación en la institucionalización de las Relaciones Industriales, 1969-1972, coincidió con un proceso de gran polarización político-ideológico que desgastó violenta y trágicamente la convivencia en la sociedad y en las universidades chilenas. Ese ambiente de conflictividad colectiva fracturó el respaldo legitimador de que había gozado la Unidad de Relaciones Industriales en la Facultad y en la Universidad de Chile, particularmente cuando como resultado de la Reforma Universitaria se decretó el término de los Institutos (Lawrence, 2013). Ese dictamen afectó la existencia de esa Unidad porque su identidad estuvo históricamente arraigada al Instituto de Organización y Administración de Empresas (INSORA), el que estaba forzado a su desaparición. Eso significó para la URI una enorme incertidumbre respecto de su devenir institucional. Sin embargo, la URI consiguió durabilidad cuando las autoridades de la Facultad, en 1972, le otorgan a la Unidad el estatus jurídico de 
Departamento. Esa conversión correspondió a una acción oportunista de las autoridades, quienes aprovechando la ambigüedad del nuevo Estatuto producto de la Reforma, que establecía que Facultades, Escuelas y Departamentos eran las únicas instituciones para el trabajo universitario, se sirvieron del subterfugio de convertir a la URI en el Departamento de Relaciones del Trabajo y Desarrollo Organizacional (DERTO). Con esa conversión, paradojalmente, la URI termina su declinación con un repunte institucional de mayor rango académico y de aparente mayor prestigio (Mahoney y Thelen, 2010).

El tercer ciclo, 1973, está de lleno relacionado con el golpe militar, que por medio de la fuerza, accede al gobierno de la nación. Prontamente, después de esa intervención, los nuevos gobernantes establecieron la estructura orgánica de la Universidad de Chile que ratificó a la Facultad de Economía y Ciencias de la Administración (FACEA) dedicada al estudio y enseñanza de esas disciplinas en la Universidad de Chile, con lo que también se ratificó la identidad del DERTO.

Esos tres ciclos conformaron la primera fase del proceso de construcción de la disciplina de GRH en la FEN, a la que se suceden varias otras etapas que tienen que ver con las rupturas históricas que se desencadenaron en la sociedad chilena a partir de 1973, con el término de la democracia, el fin del Estado empresarial y con la instalación del neoliberalismo (Salazar, 2015). Consideramos que esas rupturas transformaron de manera determinante las relaciones de trabajo y de empleo en Chile, afectando el rumbo que tomó la GRH en empresas y organizaciones. Eso, a nuestro entender, amerita nuevos estudios que cubran las sucesivas etapas para el caso de la FEN considerando la fase fundacional al que ha referido esta investigación.

Finalmente consideramos que este trabajo contribuye al conocimiento de la historia de la GRH en Chile, particularmente en universidades, asunto que al parecer no ha tenido mayor interés en investigadores locales. La narrativa que se ha hecho es un 
cuestionamiento a la reificación respecto de cómo se estudia y practica actualmente la GRH en la FEN, con total desconocimiento de sus orígenes históricos. Eventualmente lo aquí realizado pueda estimular a revertir esa exclusión permitiendo conciencia de esos orígenes en el entendimiento actual de la GRH en la FEN y en el contexto más amplio de las organizaciones chilenas (Berger y Pullberg, 1965).

\section{Referencias}

AleXANDROv, H. (2009), "Experiencing know ledge: The Vicissitudes of a Research Journey". In S. Clark, y P. Hoggett (Eds.). Researching Beneath the Surface (pp. 29-49). London, UK: Karnac.

Alvesson, M., y K. Sköldberg (2004), "Reflexive Methodology", London, UK: Sage Publications.

Alvesson, M., K. Ascraft y R. ThOMAs, R. (2008), "Identity matters: reflections on the construction of Identity scholarship in organizations studies", Organization, Vol 15(1), pp. 5-28.

AmDAM, R.P. (2013), "Business Education", en G. Jones y J. Zeitlin (Edts), The Oxford Handbook of Business History, pp.581-60, Oxford University Press. U.K.

ARMSTRONG, A. (1975), "El Sistema de Relaciones Industriales chileno y la necesidad de cambio", pp.7-42. En A. Armstrong; G. Boroscheke; F. Walker; D. Piccinni; y J.A. Muga (Eds) El Futuro de las Relaciones Industriales en Chile. Editorial Nascimento, Santiago, Chile.

ARMSTRONG, A. (2013), "El Instituto de Organización y Administración (INSORA) de la Universidad de Chile", Documento sin publicar. Santiago, Chile.

BARRERA, M. (1969), “Algunos aspectos no económicos de la integración latinoamericana", Ediciones INSORA.

BARRÍA, J. (1967). "El convenio colectivo en la industria del cuero y calzado", Ediciones INSORA. 
Berger, P. y S. Pullberg (1965), "Reification and the Sociological Critique of Consciousness", History and Theory, Vol. 4, No 2, pp. 192-211.

BoJE, D.M. (2001), "Narrative Methods for Organizational y Communication Research", London: Sage Publications.

BoroscheK, G. (1975), “Organización Social de la Economía”, pp. 43-85. En Armstrong et. al. (Eds). El Futuro de las Relaciones Industriales en Chile. Editorial Nascimento, Santiago, Chile.

BRINT, S. y J. KARABEL (1991), "Institutional Origins and Transformations: The Case of American Community Colleges", pp. 337-360, en W.W. Powell y P.J. DiMaggio (Edts), The new institutionalism in organizational analysis, The University of Chicago Press.

Buchelli, M. y D. WADhWAmi (Eds.), “Organizations in Time”, Oxford, USA, Oxford University Press.

BuCHELI, M. y J. KIM (2014), “The State as Historical Construct in Organization Studies", in M. Buchelli M. y D. Wadhwami (Eds.), Organizations in Time, pp. 241-262, Oxford, UK:Oxford University Press.

Clavel, C. (1984), "La Universidad de Chile: 50 Años de Historia Académica", Revista de Economía, Vol 29, Universidad de Chile.

Clegg, S. C. Rhodes y M. Kornberger (2007), "Desperately Seeking Legitimacy: organizational Identity and emerging Industries", Organization Studies, Vol 28(4), pp. 495-513.

CzarniawskA, B. (2004), Narratives in Social Science Research, London: Sage Departamento de Economia (2009) Economistas de la U 1934-2009. Departamento de Economía. Santiago, Chile.

DutTon, J. y DuKerich, J. (1991) Keeping an eye on the mirror: Image and Identity in Organizational Adaptation. Academy of Management Journal 34(3): 517-554.

DiMaggio, P. y Powel, W.W. ( 1991) “Introduction”; pp.1-38. In W.W.Powell y P.J.DiMaggio (eds) The New Institutionalism in Organizational Analysis. Chicago, University of Chicago Press.

ECONOMÍA y AdMINISTRACIÓN (2014), Facultad de Economía y Negocios, 80 años 1934-2014. Noviembre-Diciembre, No 163. 
FEAR, J. (2014), "Mining the Past: Historicizing Organizational Learning and Change", pp.169-19, in M. Buchelli,y D. Wadhwami (Eds.). Organizations in Time Oxford, USA: Oxford University Press.

FuCHS, C. y L. SANTiBÁÑEz (1967, "Pensamiento, Política y Acción del Ejecutivo Industrial Chileno", Ediciones INSORA.

GARRETÓN, M. y J. MARTíNEZ (1985), "Universidades Chilenas: Historia, Reforma e intervención”, Ediciones Sur, Santiago de Chile.

GiOIA, D. y K. ChitTiPEDDI (1991), "Sense making and sense giving in strategic change initiation”,. Strategic Management Journal, Vol 12, pp. 433-448.

Gioia, D. K. Price y J. ThOMAS (2010), "Forging and identity: an insider-outsider study of processes involved in the formation of organizational identity", Administrative Science Quarterly, Vol 55, pp. 1-46.

Gospel, H. (2013), "The management of labor and human resources", en G. Jones y J. Zeitlin (Edts), The Oxford Handbook of Business History, pp.420-446.Oxford University Press. U.K.

Greenwood, R., C.R. Hinings y D. Whetten (2014), "Rethinking Institutions and Organizations", Journal of Management Studies, Vol 51:7, pp.1206-1220 November.

HALL, P. (2010), "Historical institutionalism in rationalist and sociological perspective", in J. Mahoney y K. Thelen (Eds.), Explaining Institutional Change Ambiguity, Agency and Power, pp. 204-223, Cambridge: Cambridge University Press.

HARDY, C. y S. MAGUIRE (2013), “Institutional Entrepreneurship”, pp. 198-217, en Greenwood; Oliver; Sahliny Suddaby (edts.), The Sage Handbook of Organizational Institutionalism, Sage Publications.

HASSARD, J.S. (2012), "Rethinking the Hawthorne Studies: The Western Electric research in its social, political and historical context",. Human Relations, Vol 65(11), PP. 1431-1461.

Hoggett, P. (2013), "Haciendo Investigación Psicosocial”, en E. Acuña, y M. Sanfuentes (Eds.), Métodos Socioanalíticos, pp. 59-78. Santiago, Chile: Editorial Universitaria. 
HighHouse, S. (2002), "A History of the T-Groupand Its Early Applications", Management Development. Group Dynamics: Theory, Research and Practice, Vol. 6, No 4, PP. 277-290.

I.A.P. (1963), Memoria del Congreso Interamericano de Administración y Dirección de Personal. Santiago Chile.

INSORA (1962), "Estudio de Recursos Humanos de nivel Universitario en Chile", Edición Insora.

Kaufman, B.E. (2008), "The Development of HRM in Historical and International Perspective", P. Boxal et al. (Eds), The Oxford Handbook of Human Resource Management, pp.20-47. Oxford University Press.

KerR, C., J.T. Dunlop, F.H. HARBISON y CH Myers (1963), “El Industrialismo y el Hombre Industrial", INSORA y Editorial Universitaria de Buenos Aires.

LANDSBERGER H.A. y F. CANitrot (1967), “Iglesia, intelectuales y campesinos". Editorial del Pacífico.

LANDSBERGER, H.A. y R. DASTRES (1964), "La situación actual y el pensamiento del administrador de personal chileno", Ediciones INSORA.

LAWRENCE, TH. (2013), "Power, Institutions and Organizations", pp. 170-197, en Greenwood; Oliver; Sahliny Suddaby (edts.), The Sage Handbook of Organizational Institutionalism, Sage Publications.

MAHONEY J., y K. Thelen (2010), “A Theory of Gradual Institutional Change”, in J. Mahoney, y K. Thelen (Eds.), Explaining Institutional Change (pp. 1-37). Cambridge, USA: Cambridge University Press.

McKersie R., A. Hochan y Harry C. KATZ (1986), "The Transformation of American Industrial Relations", Basic Books, 1986.

Millward, R. (2013), "Business and the State", en G. Jones y J. Zeitlin (Edts). The Oxford Handbook of Business History, pp.529-557, Oxford University Press. U.K.

Mönckeberg, M. O. (2006) La Privatización de las Universidades, Una Historia de Dinero, Poder e Influencias. Editorial Copa Rota, Santiago, Chile. 
Montecino, S. y M.E. Acuña (2013), "Las Huellas de un Acecho”, Anales de la Universidad de Chile, Editorial Catalonia.

MORRIS, J. (1967), "Las élites, los intelectuales y el consenso", Editorial del Pacífico, Santiago, Chile.

MugA, J. A. (1975), "Las Relaciones Industriales en la Empresa”, pp. 191-211, en Armstrong et. al. (Eds), El Futuro de las Relaciones Industriales en Chile, Editorial Nascimento, Santiago, Chile.

O’CONNOR, E.S. (1999) “The Politics of Management Thought: A Case Study of the Harvard Business School and the Human Relations School", The Academy of Management Review, Vol. 24, N1, Jan. pp.117-131.

PALMA, L. (1974), “Reseña Histórica. La Facultad de Ciencias Económicas 19341972”, Publicación Facultad de Ciencias Económicas, Santiago, Chile.

Pedreros, P. y F. TrincAdo (2014), "Historia del Área de Recursos Humanos en la Facultad de Economía y Negocios (FEN), de la Universidad de Chile", Tesis de grado para optar el grado de Magíster en Gestión de Personas y Dinámica Organizacional. Escuela de Postgrado FEN. Santiago, Chile.

PERrow, Ch. (1990), "Sociología de las Organizaciones”, McGraw-Hill/ Interamericana de España, S.A.

PiCCINNI, D. (1975), "Proyección del Sindicalismo en Chile", pp. 141-160, en Armstrong et. al. (Eds), El Futuro de las Relaciones Industriales en Chile. Editorial Nascimento, Santiago, Chile..

Riveros, L. (2016), Tres Siglos Venciendo Fronteras. El Devenir Institucional de La Universidad de Chile. Ediciones Radio de la Universidad de Chile, Santiago.

Salazar, G. (1990), La Violencia Política Popular en las Grandes Alamedas, Ediciones LOM, Santiago, Chile.

SALAZAR, G. (2015, La enervante levedad histórica de la clase civil (Chile19001973), Eitorial Debate, Santiago Chile.

Salazar, G. y J. PINTo (2002), Historia Contemporánea de Chile III, Ediciones LOM, Santiago, Chile. 
SCHEIN, E. (1985) Organizational Culture and Leadership. Jossey-Bass, California.

ScoTt, R. (2014), Institutions and Organizations Ideas, Interests, and Identities, London, UK: Sage.

SElume, J. (1986), "La Universidad de Chile y su contribución al desarrollo económico nacional", Anales de la Universidad de Chile, Vol. 3, pp. 43-60, Universidad de Chile.

SELZNICK, P. (1957), Leadership in Administration a Sociological Interpretation, California, EUA: University of California Press.

SElzNick, P. (1996), "Institutionalism "Old" and "New"”, Administrative Science Quaterly, Vol. 41, pp. 270-277.

SILVA, F. (2012), "Un Contrapunto de Medio Siglo: Democracia Liberal y Estatismo Burocrático", pp.751-869, en S. Villalobos et al. (Eds), Historia de Chile. Editorial Universitaria. Santiago, Chile.

SKOCPOL, Th. (1995), "Why I am an Historical Institutionalist", Polity, Vol. 28, pp. 103-106.

Suchman, M. (1995). Managing Legitimacy: Strategic and Institutional Approaches.The Academy of Management Review, 20(3), 571-610.

Suddaby, R., W. Foster y A. Mills (2014), "Historical Institutionalism", in M. Buchelli, y D. Wadhwami (Eds.), Organizations in Time (pp. 100-123) Oxford, USA:Oxford University Press.

SunKEL, O. (2011), "Capítulo IV, La gran crisis de 1930 y el auge y decadencia de la industrialización sustitutiva, 1930-1970", pp.167-195, en El Presente como Historia. Catalonia, Santiago, Chile.

VALDÉS, J.G. (1989), “La Escuela de Chicago: Operación Chile”, Grupo Editorial Zeta S.A. Buenos Aires,.Walker, F. (2003). Derecho de las Relaciones Laborales, Editorial Universitaria, Santiago, Chile.

WALKer, F. (1975), "Visión Retrospectiva del Movimiento Sindical de Chile", pp. 141-160, en Armstrong et. al. (Eds), El Futuro de las Relaciones Industriales en Chile. Editorial Nascimento, Santiago, Chile.

WALKER, F. (2003), "Derecho de las RelacionesLaborales", Editorial Universitaria, Santiago, Chile. 
